por ello vamos a examinar, brevemente, el caso concreto del Principado de Andorra, que ya poco antes de la Constitución de 1993 optó por una estrategia de acercamiento gradual y progresivo hacia la UE. El proceso de acercamiento a la UE se ha desarrollado en tres fases. La primera tuvo un carácter aduanero y comercial y se concretó en el Acuerdo en forma de canje de notas entre la Comunidad Económica Europea y el Principado de Andorra, de 28 de junio de 1990, en vigor desde el 1 de julio de 1991, que creó una unión aduanera entre Andorra y la CE para los productos industriales. Quedaron excluidos de la unión, pero no del Acuerdo, los productos agrícolas y alimenticios. En 1997 se firmó el Protocolo sobre cuestiones veterinarias, complementario del Acuerdo de 1990. Mencionemos también el Apéndice a las reglas de origen del año 1999, importante para la exportación de productos agrícolas transformados. En la segunda fase Andorra intenta conseguir un nuevo encaje en la UE con la integración de nuevos ámbitos que fueran más allá de las aduanas. Se concretó en el Acuerdo de cooperación entre el Principado de Andorra y la Comunidad Europea, de 15 de noviembre de 2004, en vigor desde el 1 de julio de 2005. También pertenece a esta fase el Acuerdo entre el Principado de Andorra y la Comunidad Europea relativo al establecimiento de medidas equivalentes a las previstas en la Directiva 2003/48/CE del Consejo en materia de fiscalidad de los rendimientos del ahorro en forma de pago de intereses, de 15 de noviembre de 2004, en vigor desde el 1 de junio de 2005. A este último Acuerdo se añadió un Memorándum que hace referencia, entre otras cosas, a la adopción de negociaciones para un acuerdo monetario y para definir un campo de aplicación de la cooperación económica y fiscal más amplio. El Acuerdo monetario entre la UE y el Principado de Andorra fue firmado el 30 de junio de 2011 y entró en vigor el 1 de abril de 2012.

5. La tercera fase se inicia, oficialmente, con la Decisión del Consejo de la UE de autorizar la apertura de negociaciones con los Estados de pequeña dimensión territorial, de 16 de diciembre de 2004, si bien el proceso de aproximación al Mercado interior Europeo comenzó por iniciativa andorrana el 5 de mayo de 2010, con un Documento informal de reflexión, presentado por el Gobierno andorrano a la Comisión Europea, en el que se pedía un nuevo acuerdo que permitiera avanzar en la ampliación de las relaciones con la UE, con el fin de suprimir las fronteras con la Unión respecto del control de mercaderías y aumentar el grado de integración económica. Se pedía, lógicamente, un trato ad hoc sobre ciertos aspectos de las libertades de circulación y establecimiento, porque una aplicación automática del acervo comunitario podría comportar consecuencias problemáticas para un pequeño Estado. Ha habido ya reuniones para revisar el Acuerdo sobre fiscalidad, a iniciativa de la UE, y ya comenzarán en el 2015 las reuniones sobre el Acuerdo de asociación. Ambas negociaciones tienen un contenido diferente y no están interrelacionadas aunque coincidan en el tiempo. Dejemos constancia de que la propuesta de asociación ofrecida por la UE a Andorra, Mónaco y San Marino en relación con el Mercado interior Europeo es un caso único, sin precedentes.

Ramon VIÑAS FARRÉ

Universitat de Barcelona

http://dx.doi.org/10.17103/redi.67.1.2015.4b.03

\title{
4. LA NUEVA LEY 14/2014 DE NAVEGACIÓN MARÍTIMA DESDE LA ÓPTICA DEL DERECHO INTERNACIONAL PRIVADO
}

1. La transcendencia y particularidad que el Derecho del transporte marítimo despliega en el comercio internacional constituye el hilo conductor de esta reflexión 
que persigue, desde una dimensión y enfoque internacionalprivatista, identificar diversas cuestiones controvertidas y jurídicamente relevantes que se hallan presentes en el contenido de la nueva Ley de Navegación Marítima adscritas al ámbito del ejercicio efectivo de la actividad de porteador marítimo.

2. La nueva Ley 14/2014 representa sin duda, y pese a aspectos susceptibles de crítica desde nuestra perspectiva de análisis iusinternacionalprivatista, un avance normativo muy significativo, al permitir dotar a nuestro ordenamiento jurídico de un marco legal moderno y sistematizado, que fomenta además una mayor seguridad jurídica y previsibilidad.

Este nuevo texto normativo requiere un examen en profundidad, con el propósito de analizar cómo tratar de proyectar sobre el ámbito internacional las problemáticas específicas que afloran en el sector del Derecho del transporte marítimo europeo e internacional como consecuencia de la interacción de los distintos bloques normativos en presencia, e interesa destacar aquellas instituciones que requieren un tratamiento diferenciado desde la óptica del Derecho internacional privado.

3. Ante las diversas aproximaciones que el Derecho del transporte marítimo permite en lo concerniente a su objeto de estudio, debe siempre abordarse una imprescindible tarea delimitadora que observe la vertiente de Derecho privado correspondiente a nuestra disciplina, sin descuidar otras que indisponiblemente tendrán que ser acometidas con la finalidad de dar una respuesta analítica acorde con las características propias del Derecho internacional privado actual, condicionado por la precisión atributiva del tráfico externo y una sugerente especialización por sectores (véanse a Álvarez Rubio, J. J., Las Lecciones Jurídicas del Caso Prestige: Prevención, Gestión y Sanción frente a la contaminación marina por hidrocarburos, Pamplona, Aranzadi, 2011, pp. 1 y ss.; GonzÁlez CAMPos, J. D., «Diversification, Spécialisation, Flexibilisation et Matérialisation des règles de Droit International Privé», $R$. des $C$., 2002 , t. 287 , pp. 156 y ss.).

La nota de internacionalidad del Derecho del transporte marítimo y la tendencia hacia su uniformidad normativa internacional delimitada hoy por la europeización del Derecho privado tras la entrada en vigor del Tratado de Lisboa y la proyección o dimensión externa de este proceso [BorRÁs, A., «La comunitarización del Derecho internacional privado: pasado, presente y futuro», Cursos de Derecho Internacional de Vitoria-Gasteiz (2001), Vitoria-Gasteiz, Servicio de Publicaciones de la Universidad del País Vasco, 2002, pp. 285-318], refleja claramente una problemática específica en territorio europeo debido a la coexistencia en el sector de bloques normativos diferenciados (FERNÁNDEZ RozAS, J. C., «La comunitarización del Derecho internacional privado y Derecho aplicable a las obligaciones contractuales», RES, 2009, núm. 140, pp. 600 y ss.).

4. La primera conclusión que cabe inferir del contenido normativo de la nueva Ley de Navegación Marítima es que el resultado normativo final se ha visto enriquecido respecto al trabajo previo y apreciable en los anteproyectos y proyectos que precedieron a la ley, y esto queda constatado en una redacción más cuidada y completa de toda la dimensión internacional. Pese a esta valoración global positiva, no cabe obviar que por momentos el legislador parece articular como una especie de «Guadiana normativo» al Derecho europeo, y olvida por momentos incorporar la referencia expresa al Derecho europeo/comunitario.

La nueva ley parece, por momentos, no advertir el transcendental protagonismo que ostenta el bloque normativo europeo para este particular sector comercial. Como 
aporte hermenéutico, debe tenerse en cuenta que no hay referencia alguna al Derecho europeo a lo largo del preámbulo a excepción de la indicación de pertenencia de España al ámbito comunitario europeo, que no Unión Europea, para subrayar que dicha realidad conlleva mayores exigencias en materia de responsabilidad por contaminación marítima; se trata, por tanto, de una escueta referencia a las exigencias que establece el Derecho de la UE en materia de seguros de grandes riesgos y una indicación sobre la aplicación preferente en materia procesal de los Convenios internacionales y las normas de la UE sobre el Derecho interno.

5. El texto carece de una pronta identificación de la magnitud y vocación internacional de sus normas que permita al operador jurídico identificar desde su inicio esta realidad. El artículo primero dedicado al objeto y ámbito de aplicación debiera haber recogido una clara referencia a dicho extremo, sin perjuicio de la referencia a la prelación de fuentes y su interpretación recogida y ubicada en el artículo segundo.

Cabe subrayar la ausencia total de referencia al Derecho europeo comunitario en el título I dedicado a la ordenación administrativa de la navegación, en concreto en los capítulos dedicados al ámbito de aplicación de las normas de policía, el régimen de estancia en aguas interiores marítimas y en puerto y al régimen general de la navegación marítima, donde se establece el articulado relativo a la lucha contra la contaminación y donde hubiese sido necesario incorporar una referencia expresa al bloque normativo europeo.

En este sentido, es muy significativa la ausencia de alusión alguna a la Ley Orgánica del Poder Judicial (art. 22) y al Derecho europeo en la redacción del art. 43, capítulo IV, concerniente al derecho de paso inocente por el mar territorial, sobre el ejercicio de la jurisdicción civil en comparación con el precepto relativo al ejercicio de la jurisdicción penal en el que sí se ha recogido tal previsión.

6. En cuanto al capítulo dedicado a la regulación del contrato de fletamento, cabría resaltar que la apuesta del legislador por respetar la autonomía de la voluntad de las partes permite consolidar una orientación acertada, en contraste con otras previsiones procesales llamativamente restrictivas de la misma. En lo positivo cabe subrayar las disposiciones concernientes a los gastos del fletamento por tiempo y por viaje (art. 204.2), la designación del muelle o lugar de carga (art. 217.1), o incluso el precepto que regula las operaciones de carga y estiba como operaciones conexas transcendentales para el efectivo transporte de las mercancías por vía marítima y la posibilidad de que las partes acuerden a quién corresponde la realización de dichas actividades y la asunción de los riesgos que puedan acontecer (art. 218).

También es necesario resaltar, respecto a la sección dedicada al conocimiento de embarque, el art. 251 de la Ley de Navegación Marítima destinado a la eficacia traslativa del conocimiento de embarque como título valor. De esta manera, habrá que valorar la exigencia que establece la norma sobre la verificación del consentimiento por parte del adquirente respecto de los acuerdos de jurisdicción y arbitraje. Es decir, que con independencia de que la transmisión del conocimiento de embarque produzca idénticos efectos a la entrega de las mercancías sucediendo el adquirente en todos los derechos y obligaciones al transmitente, el adquirente tendrá que dar su consentimiento expreso sobre los acuerdos existentes en materia de jurisdicción y arbitraje según los términos de los arts. 468 y 469. Cuestión que difiere de la consolidada interpretación jurisprudencial del TJUE (STJCE de 19 de junio de 1984, asunto Tilly Russ, 71/83; STJCE de 16 de marzo de 1999, asunto Castelletti, C-159/97; STJCE de 9 de noviembre de 2000, asunto Coreck Maritime GmbH y Handelsveen BV y otros, 
C-387/98) que sólo exige la verificación del consentimiento en aquellos casos en los que, según el Derecho nacional aplicable, el tenedor no haya sucedido al cargador en sus derechos y obligaciones.

7. Otro aspecto que cabría resaltar es la falta de previsión de la ley sobre la entrada en vigor del nuevo RBI bis, que demandaba un ejercicio de prospección futuro no acometido por el legislador, y que parece traerá consecuencias en su aplicación práctica. La Ley de Navegación Marítima recoge expresamente en el capítulo I del título IX ciertas especialidades en materia de competencia judicial internacional, concretamente en el art. 468 (cláusulas de jurisdicción y arbitraje) y en el art. 469 (criterios de atribución de competencia).

El art. 468 recoge una regla referente a los acuerdos atributivos de jurisdicción de carácter expreso que ante la inexistencia de Convenios internacionales aplicables se verá desplazada por el art. 25 del RBI bis relativo a la prórroga de la competencia. Un art. 25 que permite a las partes, con independencia de su domicilio, acordar el sometimiento de sus controversias a los tribunales de un Estado miembro.

La norma contenida en el art. 468 recoge una interpretación restrictiva de la derogatio fori de los Tribunales españoles ante la existencia de un acuerdo atributivo de jurisdicción a un tribunal extranjero o a un arbitraje en el extranjero, advirtiendo de la nulidad de toda cláusula que no haya sido negociada de forma individual y separada al contrato principal (véase DE Miguel Asensio, P. A., "Los acuerdos de jurisdicción en la nueva Ley de Navegación Marítima», 17 de septiembre de 2014, recuperado de http:// pedrodemiguelasensio.blogspot.com.es/2014/10/los-acuerdos-de-jurisdiccion-en-la.html).

En consecuencia, esto supone que para aquellos casos en los que el tribunal o tribunales extranjeros designados por las partes mediante acuerdo atributivo de jurisdicción como competentes para conocer del litigio no estén ubicados en un Estado miembro del RBI bis o no sean parte de un Convenio internacional en vigor en España que contemple o ampare tal posibilidad de autorregulación procesal de las partes, será aplicable el régimen contenido en el mencionado artículo de la Ley de Navegación Marítima, debiéndose entender que si no se cumple con las condiciones exigidas por esta norma en los contratos de utilización de buque o en los contratos auxiliares de navegación, la cláusula del contrato que recoja la sumisión expresa a tribunal extranjero o a arbitraje en el extranjero será nula y se tendrá por no puesta.

En efecto, si esto fuera así, los tribunales españoles entenderán que son competentes para conocer de la controversia suscitada y llegado el caso esto podría suponer un problema de cara a la ejecución de la sentencia y respecto a su validez extraterritorial.

La consagración de la autonomía de la voluntad para la materialización de los acuerdos de elección del tribunal competente, es un debate con enorme interés para nuestra disciplina de Derecho internacional privado, que aflora en el estudio de este particular sector del Derecho del transporte internacional. En este sentido, la visión restrictiva que proyecta el art. 468 supone una limitación de la voluntad de las partes para la elección del foro jurisdiccional que no se sostiene en términos jurídicos, y refleja además una desconfianza hacia la autonomía de las partes y contraviene la consagrada práctica o costumbre y usos del sector. Desde luego, es necesario que el sistema competencial evolucione sin condicionantes hacia criterios de atribución determinados por la autonomía de la voluntad de las partes.

8. Por otro lado, debido a la entrada en vigor para España, el 14 de septiembre de 2011, del Convenio de Ginebra de 12 de marzo de 1999 sobre el embargo preventivo de buques, se mejora, sin duda, la redacción del art. 538 del Anteproyecto de Ley de 
2006 y del art. 501 del Proyecto de Ley del mismo año. Ambos preceptos incorporaban por referencia una disposición convencional que no formaba parte del Derecho interno español para regular el embargo de buque por otros créditos cuando en España todavía era aplicable el Convenio sobre embargo preventivo de buques de 1952. Este Convenio convivió con el actual texto aplicable hasta que la denuncia efectuada por España, el día 28 de marzo de 2012, desplegó sus efectos.

Aun así, la regulación recogida por esta nueva Ley de Navegación Marítima sobre el embargo preventivo de buques no queda exenta en la actualidad de debate jurídico en relación con el art. 31 del RBI sobre medidas provisionales y cautelares (art. 35 RBI bis). Debe tenerse en cuenta que el art. 470 del capítulo II del título IX sobre el embargo preventivo de buques que recoge la naturaleza y regulación de la medida, alude a la medida cautelar del embargo preventivo remitiéndose a la aplicación de lo regulado en el Convenio sobre embargo preventivo de buques de 1999, a lo dispuesto en la propia ley y, supletoriamente, a lo establecido en la LEC, sin referencia alguna a la LOPJ, ni al Derecho comunitario (RBI y RBI bis). Ausencia nuevamente sorprendente si tenemos en cuenta que en las materias incluidas dentro del ámbito de aplicación del RBI sus disposiciones desplazan a las normas contenidas en el Derecho interno (véase ARENAS GARCíA, R., "Las medidas provisionales y cautelares en el Reglamento Bruselas I: de la regulación actual a la regulación proyectada», La Ley, 2011, núm. 7601).

La doctrina ha cuestionado y resaltado si la firma del Convenio sobre embargo preventivo de buques de 1999 por España, sin haber realizado reserva alguna respecto a la aplicación del criterio de la lex fori como criterio atributivo de competencia para conocer sobre el fondo del asunto (art. 7), podría o no suponer un incumplimiento del Derecho comunitario afectando incluso en lo concerniente al reconocimiento y ejecución de las decisiones judiciales en materia civil y mercantil (véase QuiRós DE SAS, A., "El nuevo régimen del embargo preventivo de buques en el Derecho español», Actualidad Jurídica Uría Menéndez, 2012, núm. 32, pp. 137-141).

9. En definitiva, el resultado de la nueva Ley de Navegación Marítima es satisfactorio al permitir una regulación moderna, depurada y elaborada con un alto grado de detalle. No obstante, habría algunos aspectos que hubiesen requerido un ejercicio de prospección futura, y otros que demandaban un mayor acierto en cuanto a la importancia del Derecho internacional privado comunitario como marco jurídico de carácter institucional, previsible, equilibrado y sencillo.

Además, en un sector tan complejo como el del Derecho del transporte marítimo internacional es muy positivo, sin perjuicio de las singularidades presentes en cada una de las modalidades de contratación, que un texto de estas características sea respetuoso con la libertad contractual reconocida tradicionalmente a las partes en este ámbito.

Unai BeLINTXON MARTín

Prof. Asociado de Derecho internacional privado

Universidad Pública de Navarra

http://dx.doi.org/10.17103/redi.67.1.2015.4b.04

\section{24. ${ }^{a}$ REUNIÓN DEL GRUPO EUROPEO DE DERECHO INTERNACIONAL PRIVADO (FLORENCIA, 19 A 21 DE SEPTIEMBRE DE 2014)}

1. La 24. ${ }^{\mathrm{a}}$ reunión del Grupo Europeo de Derecho Internacional Privado (en adelante, GEDIP) tuvo lugar en Florencia (Italia), los días 19 a 21 de septiembre de 2014 